\title{
Infancia y vejez en la poesía de Nadia Contreras.
}

\section{Childhood and senectitude in the poetry of Nadia Contreras.}

\author{
Krishna Naranjo Zavala \\ Facultad de Letras y Comunicación / Universidad de Colima (MÉXICO) \\ CE: krish@ucol.mx \\ Félix Alejandro Delgadillo Zepeda \\ Maestría en Estudios Literarios Mexicanos / Universidad de Colima (MÉXICO) \\ CE: alejandroloboespejo@hotmail.com
}

DOI: $10.32870 /$ sincronia.axxiii.n76.13b19

$\mathrm{BY}$ - NC

Esta obra está bajo una Licencia Creative Commons Atribución-NoComercial 4.0 Internacional

Recibido: $13 / 12 / 2018$

Revisado: 04/03/2019

Aprobado: 01/04/2019

\section{RESUMEN}

El objetivo del trabajo es explorar, en la poesía de Nadia Contreras, la representación de dos facetas vitales en el ser humano: la infancia y la vejez. Temáticas que podemos constatar en casi toda su obra poética. Nos centraremos en Quedará el vacío (2017), Caleidoscopio (2013), Cuando el cielo se derrumbe (2007) y Retratos de mujeres (1999). Se abordarán desde un ejercicio hermenéutico a partir de planteamientos de María Zambrano y Gaston Bachelard, principalmente. Asimismo, acudiremos a Bataille para acercarnos a la corporalidad y a la vejez, temas latentes en el primer poemario de la autora.

Palabras clave: Nadia Contreras. Poesía. Infancia. Vejez. Poeta contemporánea. 


\begin{abstract}
:
The objective of this work is to explore, in the poetry of Nadia Contreras, the representation of two vital stages of the human being: infancy and elderly. As both themes can be traced through most of her poetic works. We will focus on Quedará el vacío (2017), Caleidoscopio (2013), Cuando el cielo se derrumbe (2007) and Retratos de mujeres (1999). They will be approached with a hermeneutic exercise based primarily on María Zambrano and Gaston Bachelard's oncomings. Likewise, we will approach corporality and senectitude, latent themes in her first poems, with Bataille's ideas.
\end{abstract}

Keywords: Nadia Contreras. Poetry. Childhood. Senectitude.

El objetivo del trabajo es explorar, en la poesía de Nadia Contreras, la representación de dos facetas vitales en el ser humano: la infancia y la vejez. Temáticas que podemos constatar en casi toda su obra poética. Nos centraremos en Quedará el vacío (2017), Caleidoscopio (2013), Cuando el cielo se derrumbe (2007a) y Retratos de mujeres (1999). Se abordarán desde un ejercicio hermenéutico a partir de planteamientos de María Zambrano y Gaston Bachelard, principalmente. Asimismo, acudiremos a Bataille para acercarnos a la corporalidad y a la vejez, temas latentes en el primer poemario de la autora.

Originaria de Quesería, Colima, Nadia Contreras (1976) se caracteriza por ser una escritora prolífica y activa del panorama literario nacional. Pero tiene una fuerte presencia con contextos regionales: Colima y Coahuila, en el último estado reside. Gracias a su obra y labor en el ámbito cultural. Nadia Contreras se posiciona como un referente en la poesía mexicana actual. Escribe sobre todo poesía, pero también ha publicado narrativa. Es responsable de "Bitácora de vuelos", proyecto editorial en línea donde colaboran autores de distintas partes del país y se difunden acontecimientos literarios del horizonte nacional. Podría decirse que Nadia Contreras ha hecho de la literatura, su punto de referencia: ejerce la escritura, la labor editorial y la docencia en este ámbito. 
La poeta pertenece a la generación de escritores colimenses nacidos en la década de los setenta. Sin embargo, hay quienes son de otros estados, pero formaron o forman parte de la dinámica literaria de la entidad. Sin pretensión de fijar u omitir nombres, situamos a José Barocio (Michoacán, 1970), Sergio Briceño (Colima, 1970), Avelino Gómez (Manzanillo, Colima, 1973), Rogelio Guedea (Colima, 1974), Ada Aurora Sánchez (1972) ${ }^{1}$. Contreras concedió una entrevista a la revista electrónica de literatura, El coloquio de los perros (Caraza, 2016), donde mencionó sus primeras lecturas: Amado Nervo, Carlos Pellicer, Xavier Villaurrutia, Salvador Novo, Rosario Castellanos, Sylvia Plath, Alejandra Pizarnik. Estas referencias muestran sus búsquedas e influencias literarias. Dado que su producción poética es constante, como lectores nos enfrentamos a diversas facetas líricas, sin embargo, advertimos preocupaciones estéticas.

Las valoraciones críticas sobre su obra convergen. Sobresalen las representaciones femeninas y el núcleo familiar. Sánchez y Vergara (2014) sostienen que, pese a la pertinencia social que resulta escribir en torno a la imagen de la mujer en situaciones íntimas y sociales, no se vislumbra alguna militancia. Se trata de un "canto desgarrador" de quien percibe la vida en un "ritmo poético confesional" (p. 279). Ceballos y Romero (2014) puntualizan que la poeta "indaga los orígenes familiares". Asimismo, y en sintonía con el juicio anterior, se insiste en este ritmo, "el paso del tiempo resuelto en desmemorias, las tribulaciones de los buscadores del amor, las palabras maternales, los lugares más bellos de la sensibilidad, los parajes menos transitables de la historia personal" (p. 71).

\section{Infancia como memoria y diálogo interno}

Con el poeta chileno, Jorge Teillier (2017) observamos la infancia como una fase del desarrollo humano que puede estar lejos de ser modélica. Una primera mirada a esa etapa, sostiene, se enlaza con la idea de "la edad de oro", sin embargo, una segunda mirada "descubre una imagen que suele permanecer escondida [...]: que la infancia no es solo dominio de la pureza, sino que también allí los

\footnotetext{
${ }^{1}$ Sugerimos la lectura del capítulo "Mujer, identidad y escritura en dos poetas colimenses del siglo XX" de las autoras, Ada Aurora Sánchez y Gloria Vergara (2014).
} 
ángeles de las tinieblas extienden sus alas". En la poeta, el tema adquiere matices, puesto que, por un lado, se desea acudir a dicho periodo; por otro, se confiesa el caos que éste representa. Nos centraremos en dos poemarios, partiendo de que, en ambos, la voz lírica atestigua la pérdida y recuperación de la infancia mediante el ejercicio de la memoria. Proponemos que su poética puede concebirse en sintonía con la visión del arte que aporta María Zambrano, particularmente en la denominación que la filósofa da sobre la elegía, subrayando elementos esenciales: nostalgia, memoria, olvido. De igual modo, los planteamientos de Gaston Bachelard, quien ve a la infancia expresándose en la ensoñación, nos permite hacer visibles, en la poesía de Nadia Contreras, la memoria, el dolor en la evocación de un pasado y el tono filosófico que la voz lírica expresa sobre este periodo.

En Cuando el cielo se derrumbe (2007a), vemos temas claves en la poética de Contreras: el decaimiento del ser, la vejez mediante la figura de la abuela, la soledad y la muerte. Asimismo, la presencia de los gatos. La voz lírica observa, lúcida, sucesos de lo cotidiano que parecen desplomarse entre brumas; prevalece una estética del dolor donde el cuerpo encarna esta sensación. Centrándonos, primeramente, en la infancia, notamos que se sitúa en un contexto familiar. En este sentido, los padres han dejado huella, una especie de herida en la memoria que acude a episodios dolorosos.

Tú que sabes del miedo,

de una maleta que se rehace cada noche

como una batalla

perdida de ante mano.

Él es mi padre.

Digo padre y un adolescente se juega la vida.

Sé que mi madre lo deseaba, se enamoró como ninguna otra mujer y su cuerpo fue el cuerpo de la herida, 
la sangre, el pulmón roto por el llanto.

Nadie lo ve partir, nadie

abordar ningún barco.

Sólo yo: la niña desfigurada por el tiempo.

(p. 37)

La voz lírica ofrece un testimonio sobre los encuentros y desencuentros de los padres; en el cierre del poema se revela la infancia. Para Zambrano (2006), "el poeta sueña con su infancia y quiere recuperarla, entrar de nuevo en el jardín irreconquistable que hay al comienzo de cada vida" (p. 71). Esta voz poética da cuenta, a manera de elegía, la evocación de un pasado que repercute en la autopercepción: "niña desfigurada por el tiempo". En palabras de la filósofa:

la elegía es el momento en que la poesía toma conciencia de su nostalgia propia, de su propia memoria y de su olvido. Nace el llanto, la elegía, que es soledad y lamento por haber conocido un mundo con el que resulta imposible intimar definitivamente, imposible también no intimar; el llanto por la imperfecta posesión, llanto por la manchada castidad, por la inocencia perdida sin compensación. Llanto por el fracaso sin remedio de todo amor, dañado ya en su raíz. (p. 73)

Podríamos afirmar con Zambrano que la infancia es un "irresistible afán, nacido de la nostalgia de un tiempo perdido [...]" (p. 65). Sin embargo, es también un referente vital, así lo leemos en este breve poema: "Una niña nace de mí en el caos / sólo para probar que existo / Que pertenezco / finalmente / al reino de los vivos" (s/p). La conciencia sobre el ser que se declara en el poema, nos remite al hallazgo filosófico. Bachelard nos dice: "Hay horas en la infancia en las que todo niño es un ser asombroso, el ser que realiza el asombro de ser. Descubrimos así, en nosotros una infancia inmóvil, una infancia sin devenir, liberada del engranaje del almanaque" (2014, p. 177).

Cabe señalar que la voz lírica de los poemas abordados, no enuncia desde la infancia "real" sino desde la madurez arrojada a la indagación de la memoria donde sobreviene la infancia o, en 
palabras de Bachelard, "un estado del alma". En el primer poema citado, la voz lírica interpela y narra a una segunda persona, vivencias que conforman una retrospectiva familiar dolorosa. Es entonces cuando al final del poema se plantea la conciencia del ser. Este ser, en la autora, es un ser desmadejado. En el segundo poema, la voz enuncia que aflora - como un arma de salvación - la niña que nace de sí misma.

Caleidoscopio (2013), libro de poesía cuyo rasgo sobresaliente es la apuesta por el lenguaje decantado. Sin montaje retórico y desde una intención, quizá notoria, Nadia Contreras externa su verdad estética donde una voz lírica tiñe de intimidad lo nombrado: percepciones un tanto metafísicas que surgen de una sensibilidad honda frente a la naturaleza y el silencio, pasando por el tema del amor, las atmósferas que dotan experiencias sensoriales y confieren, a través de la imagen, un papel importante a la plasticidad lírica. De igual manera, aparecen rostros que integran un recuento intimista dentro del universo poético de Contreras: Salvador Dalí, estampas del surrealismo, dedicatorias a pintores como a la colimense Francisca Magaña. Vemos también a André Breton, Frida Kahlo y Leonora Carrington. Encontramos poemas breves y prosa poética. Desde luego, se menciona una suerte de definición del artefacto de espejos que da título al libro: “El caleidoscopio, / su definición, / acuario encendido / de peces" (p. 18).

En la poeta existen rasgos confesionales enmarcados, la mayoría de las veces, en un registro coloquial. Un lenguaje límpido que reconoce lo esencial. La representación de la infancia contrasta con una serie de ideales que se le atribuyen a esta etapa. En la poeta, implica el ejercicio de la memoria que registra hechos relevantes y lleva a emprender un diálogo interno para encontrar una certeza existencial: la infancia posee la textura rugosa de la costra. Nos da su definición en el siguiente poema:

Despierto a las seis, y el primer gesto que hago es tocar mi grieta [...] Se ha secado durante la noche, ha sido extraordinariamente sofocante y voluptuosa.

Estoy, por otra parte, sorprendida de que se haya secado tan pronto y de que, al to- 
carla con mi lengua, parezca un cuerpo duro que va a despegarse como una costra. Me refiero, por supuesto, a la infancia. (p. 59)

El poema, que es más bien prosa poética, mantiene el ritmo propio de la conversación, con un cierre sorpresivo que define a la infancia. Resulta fundamental la conciencia de la voz lírica en torno al tiempo porque ciertos momentos son parteaguas en la existencia, por ejemplo, el despertar y ver el impacto de la noche en la grieta de la piel. Es una escritura que atestigua la pérdida. Zambrano (2006) sostiene que el arte es el "testimonio en que el hombre vivía de otra manera o era cosa distinta de esta criatura que nos hemos encontrado siendo con extrañeza tanta" (p. 71). La poeta manifiesta este asombro frente a la costra a punto de desligarse del cuerpo, de la que, por cierto, no parece aferrarse.

En Nadia Contreras, la poesía proyecta desde un sentido elegíaco, el desvanecimiento de etapas cruciales como la infancia o la pérdida gradual de vitalidad donde se debe afrontar la condición de vejez. Por otro lado, también revela el deseo de evocar lo ausente, de recuperarlo, en cierto modo. Esta poética la podemos concebir de la mano de María Zambrano: "Hacia el arte nos dirigimos con la esperanza de recobrar esa manera de vivir perdida, ese ser extraviado de cuya falta no acabamos enteramente de convencernos" (2006, p. 71). Así, lo constatamos también en este breve texto que es una interrogante: “¿Un pájaro en su jaula es mudez o locura? / ¿Y si doy mi vuelo / a cambio de la infancia?" (s/p).

\section{Vejez y cuerpo}

Nadia Contreras en su poemario Retratos de mujeres (1999), nos muestra una preocupación por lo marginal femenino que se representa mediante el cuerpo viejo, en alquiler; el asexual. La corporalidad aparece cosificada, dócil, en abandono. Cuerpos como objetos estériles, negados a la aceptación del envejecimiento: "Son mujeres que nadie admira / antiguos cuerpos de placer" (p. 10) que también encaran el rechazo social en tanto aparecen desligados de su propia sensualidad y 
sexualidad. Se advierte, en las figuras femeninas, una negación del erotismo por la incapacidad de gestar. No son deseadas ni desean. A estos cuerpos -mudos, vedados- que también son espacios, se les niega el placer. Pierden, así, su materialidad. María Zambrano en Filosofía y poesía (2006), marca una diferencia entre los conceptos "cuerpo" y "carne", la jaula que aprisiona el alma es el primero; el segundo, lo dominado por las pasiones, vivir en cercanía de lo carnal. Sin embargo, la palabra poética será liberadora:

la apertura total de una vida a quien su cuerpo, su carne y su alma, hasta su pensamiento, sólo le sirven de instrumentos, modos de extenderse entre las cosas. Una vida que, teniendo libertad, sólo la usa para regresar allí donde puede encontrarse con todos (p. 115).

El cuerpo en alquiler, como se apuntó, es una presencia recurrente en la poética de Nadia Contreras. La figura de la prostituta aparece como desesperanza, es la "peste" familiar, la que abandona todo: los hijos, los sueños y sólo guarda la nostalgia: “¿Qué evocarán tus días de júbilo? / ¿Cuántos hombres dejarán en ti sus abismos?" (p. 13). Para George Bataille en El erotismo (2013), el cuerpo es un objeto erótico expuesto a las condiciones del deseo; suele ser una búsqueda de satisfacción, y al desnudarse se revela el deseo del otro, la posibilidad de provocar, de poseer.

La metáfora de la prostituta aparece en la poética de Nadia Contreras desde la perspectiva mitológica como la Medusa que atrapa, que petrifica con su belleza, a su vez petrificada a sí misma. Las voces femeninas no recurren a la denuncia, a la culpa o vergüenza porque existe plena conciencia de que el cuerpo tiene un precio. En el poema "Gabriela" se representa el cuerpo viejo que desea y añora un pasado; no asume su deterioro y esa añoranza de lo que fue no permite asimilar la carne deteriorada por las heridas del tiempo:

Le basta llamarse Gabriela.

Tocar sus senos al amanecer,

saber que hoy

alguien vendrá a comprarle alientos 
Se levanta con la palabra que necesita.

$Y$ todo le pesa:

Las pinturas / las mallas / el vestido corto (p. 12)

Un rasgo de la poética de Nadia Contreras es la narratividad lírica. En sus poemas sobre la infancia y la vejez, se desencadenan hechos que fluyen con ritmo propio hasta llegar al cierre donde se concentra la idea o sensación imperante. Ya advertimos en el texto que marca a la infancia como una costra, la importancia de palpar la herida para reconocerse. De manera similar lo apreciamos en el poema "Gabriela": tocarse los senos es afrontar la realidad, cobrar conciencia de sí. Más adelante, la voz lírica hace notar el papel de la memoria como vía de salvación, de mantenerse a salvo de la realidad que no es precisamente la anhelada: "Y la vida parece levantarle el ánimo, / conducirla al sitio donde el amor / un día extendió su imperio" (p. 12).

Vemos que, en los poemarios abordados, la poeta tiende a recurrir a este recuento de sucesos -percibidos desde la memoria nostálgica- para, finalmente, topar una dura realidad, alejada del encanto que proveía el recuerdo. Continúa el poema: “Pero regresa en llamas, / enferma de recuerdos / Y la vida de repente nada le ofrece / Sólo el redoble de un tambor / que le anuncia el abismo" (p. 12). A decir de las imágenes del texto que subrayan la corporalidad, la carga que implica usar maquillaje y ciertos atuendos, así como el espacio donde se resguardan los ayeres, interpretamos la existencia de una vejez asumida desde una sensación de decadencia. Dicha sensación, nos parece, se potencia con el redoble del tambor. La muerte próxima a la senectud es el reflejo que acompaña, consuela, según Jean Baudrillard en De la seducción (2001); es una tentación inmemorial: "incluso en una relación incestuosa que mantenemos con nuestra propia imagen [...] Ya que seduce porque nos consuela por la inmanencia de la muerte del sacrilegio de nuestra existencia" (p. 69). A la voz lírica no le queda más que añorar la ilusión.

En contraste con la figura femenina "Gabriela", se manifiestan las "Agraciadas". En ellas, el placer no cabe, están condenadas a no observar sus cuerpos, sentirlos, mostrarlos. Son mujeres que responden a roles sociales y morales impuestos En este poema, la voz lírica representa a mujeres 
que se han conducido por el camino de la rectitud: "Llevan el fuego / la lámpara de aceite / que las guía por la calle / sin tropiezos / Nada le piden al metal / a la de labios rojos nacida / bajo el signo de los hombres" (p. 26).

La voz lírica da voz a los prejuicios sociales que condenan ciertos comportamientos: "Llevan en la palabra la búsqueda / Son previsoras y oportunas / Nunca las he visto alrededor / de una copa de vino / porque es ahí / donde se empieza a perder la dignidad" (p. 26). En estos cuerpos representados, la seducción se ausenta, en parte, por creencias religiosas. Al respecto, María Zambrano (2006) sostiene: "el horror a la carne y a las pasiones; la soñada liberación del alma de su tumba corporal" (p. 48). Otra proyección sobre el cuerpo en relación es el de la viuda. Su corporeidad es el territorio, lastimado, que guarda el recuerdo de un amor extinto. "Camina el tiempo / vestida de negro / y con el llanto en los ojos / El destino le arrebató / al hombre / que dibujó en su vientre / el signo del amo" (p. 15). Esta mujer encarna el abandono, cuyo soliloquio, roza la locura:

\author{
De ella \\ se despide un sabor amargo \\ y ausente de toda esperanza \\ se dirige al campo \\ donde yacen las cruces \\ ¿A quién habla esa mujer \\ cuando lentamente mueve sus labios? \\ ¿Quién la espera en la puerta del abismo? (p. 15)
}

La locura es una figura que es excluida, ridiculizada, en tanto provoca temor y puede resultar una amenaza; también corresponde a aquellos sentimientos considerados negativos del ser humano: ambiciones e incluso el deseo. Para Bataille: "La humanidad aparta de sí aquello que asocia con la locura... Pero el rechazo de la locura no es más que una actitud cómoda e inevitable, que la 
reflexión tiene obligación de examinar" (2013, p. 198). Se le llama loca a quien es arrebatada por sus pasiones. Pero es una forma de denigrar, de juzgar.

Por último, cerramos con "La anciana”. La poeta marca, con un tono de fábula, la travesía de una mujer que, sin el peso atribuido a la vejez, se reencuentra con la vastedad: "Bajo el sol camina / risueña una anciana / Ayer salió de paseo al mar / Sus ojos azules se iluminaron / cuando miró la tranquilidad / de las olas" (p. 24). Esta figura femenina contrarresta con la mayoría que se encuentra en Retratos de mujeres. Existe una belleza en el reconocimiento de la ancianidad que se da, en el poema, en dos sentidos: en la mujer y en el mar.

\section{Consideraciones finales}

Nadia Contreras, en los poemarios referidos refleja distintas connotaciones en torno a las mujeres, sus identidades y sus cuerpos. Dado que su producción poética es constante, como lectores nos enfrentamos a diversas búsquedas de la autora, no obstante, es posible advertir cuestiones recurrentes. La presencia femenina cobra un amplio sitio en su territorio lírico. En palabras de Sánchez y Vergara: "La mujer vista por Nadia Contreras vive tonalidades de amargura en la soledad, en el abandono, en la prostitución, en la locura, pocas veces mostradas con esa intensidad en la poesía mexicana" (2014, p. 279). Asimismo, ambas han advertido en Contreras, el abordaje de la madre y la maternidad.

Sobre los intereses estéticos que percibimos en su poética, sobresale el tono coloquial que integra en una suerte de narratividad proyectada en los versos. También la prosa poética caracteriza la obra de Nadia Contreras. Los temas que hemos explorado, la infancia y la vejez, permiten establecer un vínculo estrecho con sus lectores puesto que son estados biológicos y psicológicos compartidos. Con Bachelard, creemos que: "Los poetas nos convencen de que todas nuestras ensoñaciones infantiles merecen ser reanudadas" (p. 160).

Alrededor de la infancia, la autora hace hincapié en la memoria, en un tiempo pretérito, lo que viene a ser un recurso poético sostenido en sus poemarios. Insiste el filósofo francés: "Para forzar el pasado, cuando el olvido nos acorrala, los poetas nos invitan a imaginar la infancia perdida. 
Nos enseñan "las audacias de la memoria"' (p. 167). En este punto, la poética de la infancia pertenece, desde luego, a sus lectores quienes pueden ser partícipes de este ejercicio de evocación.

Al abordar la vejez, la voz lírica tiende más a lo testimonial. Se da cuenta de voces estigmatizadas, de figuras que son objeto de deseo que pasan a ser objeto de exclusión. La poesía de Nadia Contreras, puede entrar en diálogo con un enfoque de género, puesto que. En Retratos de mujeres (1999), la voz lírica recorre ciertos estereotipos femeninos y nos presenta, con un guiño irónico, cómo son percibidas en función de roles impuestos, subrayando, la corporalidad del cuerpo que enfrenta su vejez o se encuentra en transición a ésta.

\section{Referencias}

Bachelard, G. (2014). La poética de la ensoñación. México: Fondo de Cultura Económica.

Bataille, G. (2013). El erotismo. México: Tusquets.

Baudrillard, J. (2001) De la seducción. Madrid: Cátedra.

Caraza, X. (2016). Nadia Contreras. El coloquio de los perros. Obtenida el 07 de septiembre de 2018. Recuperado de https://elcoloquiodelosperros.weebly.com/entrevistas/nadia-contreras

Ceballos, E. y Romero O. (Ed.) (2014). Colima Tierra de Letras. Bibliografía analítica de autores colimenses. Libros de literatura: 2001-2005. Colima, México: Universidad de Colima.

Contreras, N. (1999). Retratos de mujeres. México: Secretaría de Educación Pública.

Contreras, N. (2007a). Cuando el cielo se derrumbe. México: Dirección de Cultura de Torreón.

Contreras, N. (2013). Caleidoscopio. México: Dirección Municipal de Cultura de Torreón.

Contreras, N. (2014). Cumplimiento de la voluntad. México: Quintanilla Ediciones.

Contreras, N. (2017). Quedará el vacío. México: Pinos Alados.

Contreras, N. (2006). Filosofía y poesía. México: Fondo de Cultura Económica.

Sánchez, A. y Vergara, G. (2014). Mujer, identidad y escritura en dos poetas colimenses del siglo XX. En Kral, K, y Preciado, F. (Coord.), Interpretaciones feministas y multidisciplinarias de género (pp. 269-289). México: Universidad de Colima. 
Teillier, J. (s/d). La terrible infancia. Recuperado de:

http://www.uchile.cl/cultura/teillier/poeticas/5.html

Zambrano, M. (2006). Filosofía y Poesía. México: Fondo de Cultura Económica. 